\title{
MARIA-NOVA CONTRA O FASCISMO: A CONSTRUÇÃO DA LIBERDADE EM BECOS DA MEMÓRIA, DE CONCEIÇÃO EVARISTO
}

\section{MARIA-NOVA AGAINST THE FASCISM: THE CONSTRUCTION OF FREEDOM IN BECOS DA MEMÓRIA, BY CONCEIÇÃO EVARISTO}

https://doi.org/10.46551/21796793202000011

Henrique Marques Samyn

Universidade do Estado do Rio de Janeiro

marquessamyn@gmail.com iD 1ttps://orcid.org/0000-0002-2624-3487

RESUMO: O artigo parte da primeira obra escrita por Conceição Evaristo, Becos da Memória, para analisar a trajetória de Maria-Nova como agente de resistência em meio ao desfavelamento, percebido enquanto prática fascista. A relação de empatia que Maria-Nova constrói com as pessoas que a cercam fundamenta uma reação antifascista cujo fundamento é a afetividade, o que possibilita a construção da liberdade a partir da esperança.

PALAVRAS-CHAVE: Becos da Memória; Conceição Evaristo; fascismo; literatura afro-brasileira; literatura negro-brasileira.

ABSTRACT: The paper starts from the first work written by Conceição Evaristo, Becos da Memória, to analyze the trajectory of Maria-Nova as an agent of resistance during the process of extinction of the slums, perceived as a fascist practice. The empathic relationship that Maria-Nova builds with the people around her is based on an anti-fascist reaction whose foundation is affection, which makes it possible to build freedom from hope.

KEYWORDS: Becos da Memória; Conceição Evaristo; fascism; Afro-Brazilian literature; Black-Brazilian literature.

\section{Preâmbulo: o dever de não silenciar}

O Partido Pantera Negra definia o fascismo como "o produto da soma do capitalismo e do racismo" - um entendimento que, embora heterodoxo, tem como propósito compreender o modus operandi de um regime político que utiliza mecanismos opressores fundamentados na raça e na classe para sustentar os interesses do grande capital ${ }^{1}$. Nesse sentido, o fascismo pode ser percebido como uma estrutura que encontra sua mais evidente manifestação na brutalidade

\footnotetext{
${ }^{1}$ Cf. SAMYN, 2018, p. 41-42.
} 
policial, cujo alvo principal é a população preta e pobre, fazendo-se ainda presente em múltiplas formas de opressão e silenciamento.

No momento em que escrevo este artigo, nos primeiros meses de 2020, 0 ordenamento social e político do Brasil apresenta uma configuração essencialmente tributária do fascismo - algo que se torna visível tanto pela escalada de violência, física e simbólica, sobre as minorias, quanto por práticas autoritárias cujo efeito direto é o silenciamento dos discursos dissidentes. Nesse sentido, a disseminação do fascismo se evidencia em manifestações repressoras que cerceiam, invisibilizam e oprimem quaisquer vozes que se expressem contrariamente à vontade da elite dominante, cujo projeto de poder se concretiza em diretrizes e medidas que traduzem perspectivas reacionárias, patriarcais e colonialistas.

A partir do reconhecimento deste sombrio cenário, inclusive no que tange ao meio acadêmico - não apenas por conta da implementação de políticas cujo propósito ostensivo é coibir a produção de conhecimento, mas também devido à ação concreta de agentes reacionários que favorecem discursos e práticas antidemocráticas no âmbito universitário -, este artigo não recusa uma tomada de posição. Trata-se de voltar à primeira obra ${ }^{2}$ de uma das mais importantes vozes da literatura negro-brasileira, adotando por norte o questionamento: que tipo de estratégias esta narrativa, partícipe da produção literária de uma camada da população brasileira historicamente oprimida, pode inspirar no que tange ao enfrentamento da ordem fascista? Trata-se de atentar, sobretudo, para a trajetória de Maria-Nova - que, em meio ao cenário de devastação imposto pelo desfavelamento, ocupa a posição de agenciadora de uma resistência coletiva, por meio do acolhimento das experiências de outros habitantes da comunidade. Seja um ponto de partida o questionamento: como ler as ações de Maria-Nova como práticas antifascistas, e como compreendê-las à luz do atual cenário político brasileiro?

\section{A "memória cordial" da colecionadora}

\footnotetext{
${ }^{2}$ Becos da Memória foi a primeira obra escrita por Conceição Evaristo, embora tenha sido publicada depois de Ponciá Vicêncio.
} 
Programa de Pós-graduação em Letras/Estudos Literários da Unimontes v.21, n.1, 2020. ISSN: 2179-6793

Se, no caso de Conceição Evaristo, parte do público leitor apresenta alguma propensão a mesclar a autora empírica a seus personagens - vale recordar o texto prefacial que menciona a sessão de autógrafos na qual se requisitou certa "Ponciá Evaristo"3 - , é inegável que, no conjunto das protagonistas evaristianas, ocupa um lugar privilegiado a Maria-Nova de Becos da Memória. Com efeito, a própria natureza dessa obra, que notoriamente funde a escrita e a vida, enseja essa identificação; destarte, a própria Conceição Evaristo admite essa "parecença" com alguma frequência, embora em outras ocasiões a trate como uma "charada" - como em "Da construção de becos", texto preambular em que, não obstante, admite que a fusão da personagem narradora com a identidade da autora não a constrange ${ }^{4}$.

Cabe atentar para o modo como se configura a relação que Maria-Nova, na posição de narradora, tem com os outros personagens presentes na obra. Reduzir Maria-Nova à posição de mera compiladora das narrativas alheias, como se isso envolvesse um processo vulgar de apropriação, é um equívoco; é fundamental entender a posição de Maria-Nova como uma "colecionadora", no sentido originário do termo. Etimologicamente, "colecionar" deriva do latim collectio, cuja raiz é colligo, -igere - verbo que designa não apenas o ato de acumular elementos ao longo de um período de tempo, mas também processos de sumarização, de inferência e de construção ${ }^{5}$. Assim, Maria-Nova não opera como alguém que meramente compila histórias passivamente; seu modo de agir tem um sentido dialético e criador. A esse respeito, vale atentar para um trecho da obra que sintetiza exemplarmente o procedimento da personagem:

Um sentimento estranho agitava o peito de Maria-Nova. Um dia, não se sabia como, ela haveria de contar tudo aquilo ali. Contar as histórias dela e dos outros. Por isso ela ouvia tudo tão atentamente. Não perdia nada. Duas coisas ela gostava de colecionar: selos e as histórias que ouvia. [...] [Tio Tatão] tinha ido à guerra. Tinha histórias também. Mas, das histórias dele, MariaNova não gostava. Eram histórias com gosto de sangue. Histórias boas, alegres e tristes eram as de Tio Totó e da tia, Maria-Velha. Aquelas histórias ela colecionava na cabeça e no fundo do coração, aquelas ali haveria de repetir ainda ${ }^{6}$.

\footnotetext{
${ }^{3}$ EVARISTO, 2017a, p. 8.

${ }^{4}$ EVARISTO, 2017b, p. 12. A leitura de Oliveira (2018) tem como pressuposto essa identificação.

${ }^{5}$ A esse respeito, cf. as diferentes acepções de colligō, igere, ēgī, ectum no Oxford Latin Dictionary (GLARE, 2012, p. 385-386).

${ }^{6}$ EVARISTO, 2017b, p. 31-32.
} 
Importa não negligenciar o fato de a passagem referir, já no início, o "sentimento estranho" que habitava o peito da personagem. Essa "estranheza" evidencia de que modo Maria-Nova é movida por uma disposição invulgar, motivada menos pelo presente (ou seja: pelo ato em que, naquele momento, ela mantinha contato com as narrativas alheias) do que pelo futuro (isto é: pela certeza de que, em alguma oportunidade vindoura, a personagem contaria aquelas histórias). Isso pressupõe uma necessária clivagem entre dois âmbitos temporais: aquele em que as histórias são acolhidas, permanecendo mais vívidas na memória; e o momento futuro, já temporalmente apartado das circunstâncias de recepção. Pode-se indagar: se Maria-Nova já estava ciente da determinação para contar as histórias, por que não o fez naquele momento? Haveria, de modo sub-reptício, alguma intenção de falseamento? A resposta para essa indagação se faz presente no texto: "não se sabia como" Maria-Nova contaria as histórias ou seja: embora essa determinação já fosse por ela conhecida, a personagem ainda não dispunha dos meios necessários para encetá-la (o que pode ser entendido à luz de sua juventude).

Maria-Nova apresenta uma disposição singular para a escuta. $O$ ato de ouvir atentamente indicia uma abertura para o outro, estando aí a essência do seu proceder: a propensão ao acolhimento das experiências alheias. Trata-se, com efeito, de uma escuta ativa, que demanda a capacidade de viver intensamente aquilo que é ouvido, mesmo quando disso deriva uma dor profunda ${ }^{7}$. Essa receptividade é o que faculta, por exemplo, que Maria-Nova seja capaz de construir uma relação diferenciada com Bondade: "Coisas que ele não contava para gente grande, Maria-Nova sabia"”. Para além disso, a disposição empática da personagem propicia o recolhimento de histórias não-verbalizadas, como se percebe no caso de Mãe Joana, "mulher de poucas palavras": embora MariaVelha compartilhe algumas de suas histórias, Maria-Nova desenvolve a capacidade de intuir e ler as histórias nos olhos, "na expressão linda e triste da 
mãe"10. Um melhor entendimento de como isso ocorre pode ser propiciado pela noção de memória cordial.

A compreensão desse conceito demanda a percepção de que Maria-Nova não assume, em nenhum momento, uma postura passiva; de fato, a agência da personagem-narradora, já patente em sua mobilização empática, alcança o criterioso modo como arranja sua coleção de histórias - que envolve também a rejeição das histórias de Tio Tatão, que têm "gosto de sangue". Sabemos que Maria-Nova não desconhece as histórias de Tio Tatão: ela pode relembrar o relato acerca da guerra para a qual partiram homens escravizados, motivados pela promessa de liberdade, apenas para descobrir, quando retornaram, que para alcançá-la era preciso enfrentar um outro embate - a guerra contra a escravidão ${ }^{11}$. Contudo, a íntima recusa de Maria-Nova demonstra que as histórias de Tio Tatão permanecem aquém de um espaço particular no âmbito da memória. Importa perceber que essa postura seletiva está associada à afetividade: se a personagem prefere as histórias de Tio Totó e de Maria-Velha, assim age porque as pode colecionar "na cabeça e no fundo do coração". No fundamento dessa prática colecionadora está, por conseguinte, a memória cordial. Maria-Nova não se limita a registrar, de modo passivo e frio, as histórias que recolhe; essas histórias são imediatamente submetidas ao crivo do coração. Assim, o ato de repetição não é uma mera reprodução do que foi ouvido, mas a reconstrução das narrativas a partir da memória cordial; e essa mesma cordialidade é o que possibilita o recolhimento das histórias de Mãe Joana, por uma via inversa ao habitual: pode-se supor, com efeito, que o que ultrapassa a verbalidade é a relação afetuosa que as enlaça - uma vez que, embora pouco falasse, Mãe Joana era "uma mulher de muito amor"12. É pela via do amor, com a mediação do silêncio, que Mãe Joana conta suas histórias a Maria-Nova.

\section{A abertura para a coletividade}

A disposição para a abertura de Maria-Nova desempenha uma função

\footnotetext{
${ }^{10}$ EVARISTO, 2017b, p. 53.

${ }_{11}^{11}$ EVARISTO, 2017b, p. 56.

${ }^{12}$ EVARISTO, 2017b, p. 40.
} 
crucial em seu processo de amadurecimento. Através do contato com a alteridade, a personagem desenvolve uma compreensão crítica do mundo, a partir do entendimento de que suas experiências estão inscritas em uma coletividade. Assim lemos:

Maria-Nova estava sendo forjada a ferro e a fogo. A vida não brincava com ela nem ela brincava com a vida. Ela tão nova e já vivia mesmo. Muita coisa, nada ainda, talvez ela já tivesse definido. Sabia, porém, que aquela dor toda não era só sua. Era impossível carregar anos e anos tudo aquilo sobre os ombros. Sabia de vidas acontecendo no silêncio. Sabia que era preciso pôr tudo para fora, porém como, como? Maria-Nova estava sendo forjada a ferro e fogo ${ }^{13}$.

O forjamento de Maria-Nova se dá por intermédio de um aprendizado que nada tem de suave; não obstante, esse forçoso amadurecimento é o que a singulariza. Antes mesmo de alcançar a maturidade necessária para determinar seus próprios caminhos e para definir-se, a personagem transforma sua existência num espaço de compartilhamento. Isso a encaminha, por um lado, para a desindividualização, em decorrência do entendimento de que suas dores são também as dores alheias; não obstante, por outro lado, tudo isso se torna um fardo cada vez mais pesado.

Configura-se, desse modo, um processo dialético: Maria-Nova conhece a si mesma ao mesmo tempo em que conhece as existências que a cercam, desenvolvendo uma consciência crítica atenta à coletividade. Isso se evidencia em sua experiência escolar. Desde cedo, Maria-Nova se habitua a compartilhar seu conhecimento, tornando-se mestra de seus irmãos e das outras $\operatorname{crianças~}^{14}$; mas é preciso ressaltar que o tipo de conhecimento partilhado pela personagem não se resume à mera repetição de conteúdos estanques, visto sua postura invariavelmente questionadora. Vale recordar, aqui, o momento em que a personagem aprende o que era casa-grande, o que lhe enseja a vontade de "citar, como exemplo de casa-grande, o bairro nobre vizinho e como senzala, a favela onde morava" ${ }^{15}$ - algo que acaba não fazendo, tolhida pelo silêncio da turma,

\footnotetext{
${ }^{13}$ EVARISTO, 2017b, p. 76.

${ }_{14}^{14}$ EVARISTO, 2017b, p. 64.

${ }^{15}$ EVARISTO, 2017b, p. 73.
} 
inclusive da única outra aluna negra presente ${ }^{16}$.

De fato, o grande obstáculo com o qual Maria-Nova se depara, na escola, é a impossibilidade de construir ali uma rede de relações empáticas similar àquela que erigira na favela. Maria-Nova gostava de aprender, mas não de ir à escola: "tinha medo e vergonha de tudo, dos colegas, dos professores"17; aprender a transformar esse medo em coragem fez com que sobressaísse aos olhos dos professores.

Podemos divisar uma analogia entre essa capacidade de transmutar em coragem o medo e o poder de transformar a tristeza em ação emancipatória: em ambos os casos, há a transição desde um estado de negatividade imobilizante para um gesto de ação interventora sobre o real. Há um conjunto de momentos decisivos que possibilitam uma nítida percepção de como isso ocorre. Se as consequências do desfavelamento produzem um vazio que comove Maria-Nova ${ }^{18}$, isso é acentuado pelo banzo que the percorre o sangue - sobretudo, após o confronto com a morte de Filó Gazogênia, o que desvela para a menina a certeza da finitude ${ }^{19}$. Assim, o peso do fardo que guarda Maria-Nova se torna insuportável:

Maria-Nova andava em dias de grande banzo. Tristeza por tudo, por fatos recentes e passados. Tristeza por fatos que ela testemunhara e por fatos que ouvira. O peito, o coração da menina estava inchado de dor. Era preciso segurar a lágrima e ensaiar o riso. Saía um sorriso molhado dos olhos úmidos ${ }^{20}$.

O falseamento imposto a Maria-Nova, que a leva a dissimular a tristeza e a ocultar a dor, constitui um momento determinante em seu aprendizado, por fraturar a abertura para o mundo. Maria-Nova tanto se oferece aos outros, acolhendo as vivências e as dores alheias, que sua memória cordial se torna um repositório de tristeza; por outro lado, o encontro com a morte nela desperta o senso de urgência, disso derivando o impulso para ação.

\footnotetext{
${ }^{16}$ Esse silenciamento pode ser percebido como efeito de práticas fascistas. Voltarei a essa passagem mais adiante.

${ }_{17}$ EVARISTO, 2017b, p. 110.

${ }^{18}$ EVARISTO, 2017b, p. 87.

${ }^{19}$ EVARISTO, 2017b, p. 115.

${ }^{20}$ EVARISTO, 2017b, p. 128.
} 


\section{A construção da liberdade}

Momento decisivo é quando Tio Totó narra a Maria-Nova a passagem de Nega Tuína - fazendo com que a morte tenha, mais uma vez, uma importância crucial. Tomada pela empatia, Maria-Nova se sente "como se tudo fosse arrebentar dentro dela" ${ }^{21}$; isso nos permite pensar em uma situação-limite, na qual à personagem restam apenas duas possibilidades: sucumbir ao estado das coisas (o que implica entregar-se ao banzo) ou transformá-las (o que implica converter o desconforto em ação). E este será o caminho por ela adotado.

Vale a pena citar o extenso parágrafo que assinala esta decisão:

Maria-Nova sentia que era preciso modificar a vida, mas como? Saiu desesperadamente calma a andar pela favela. Conhecia de cor, de olhos fechados muitos becos, porém alguns ainda eramIhe estranhos. Mãe Joana nunca gostou que seus filhos fossem muito além da área em que moravam. Tinha medo, muito medo de que eles se perdessem, quando estivessem distantes de casa. Maria-Nova, entretanto, furava o cerco. Amava a mãe, mas era impossível não ir ao mundo. Passou pela área onde trabalhavam os tratores e lá estavam eles, pesadões, agarrados ao chão, esperando a labuta do dia seguinte. Observou que uma boa área da favela já tinha sido aplainada. Lembrou-se de todos os que moravam ali. Tantas e tantas famílias já haviam ido. Estariam felizes? Estava chegando o tempo do festival de bola e ninguém se movimentara ainda. Será que teria? Faltava muita gente: os que haviam ido embora e os que haviam partido para sempre. Quem este ano tiraria o samba? O som da cuíca, do atabaque e do pandeiro? Os homens-vadios-meninos haviam ido brincar no carrinho-trator... E os que ainda estavam por ali andavam sem coragem, sem muitos desejos. É impossível que tudo acabe assim, pensou a menina. Vida. É preciso, não sei como, arrumar uma vida nova para todos ${ }^{22}$.

A atitude contraditória da personagem, sua caminhada "desesperadamente calma”, evidencia seu conflito interior. Ao furar o cerco imposto pela autoridade materna, Maria-Nova efetiva a transgressão necessária para que a construção da liberdade se torne possível: a superação do medo propicia a abertura para a esperança. Quando vai para o mundo - figuração do novo horizonte de possibilidades -, Maria-Nova pondera sobre o entendimento da finitude: às mortes

\footnotetext{
${ }^{21}$ EVARISTO, 2017b, p. 135.

${ }^{22}$ EVARISTO, 2017b, p. 135-136.
} 
que já conheceu, soma-se a lembrança dos que partiram em direção a futuros incertos. O vazio do real, concretizado no terreno aplainado, corresponde ao vazio presente na alma dos que permaneceram, despojados de coragem e de desejos. Emerge, por conseguinte, o dilema: como fazer da morte uma nova vida? Não por acaso, é neste momento que a narrativa menciona a chegada do tempo de chuva, propiciador do recolhimento anterior à ação. A chuva não impede o nascimento do sol dentro de Maria-Nova, de Tio Totó, de Bondade e das crianças, como metáfora para o surgimento da esperança ${ }^{23}$.

$\mathrm{Na}$ escola, a ação transformadora de Maria-Nova se materializa em sua interpelação à professora, que a questiona sobre seu alheamento após a aula sobre a "Libertação dos Escravos". Ao alegar que, acerca dessa matéria, "teria para contar muitas vidas" ${ }^{24}$, Maria-Nova traz à tona o conflito entre o ensino formal e a experiência vivida; explicita sua percepção crítica do mundo que a cerca; demonstra como a "liberdade" jamais fora efetivamente alcançada - como ilustrado pelas trajetórias de Tio Totó, Filó Gazogênia, Bondade e as crianças da favela, entre tantos outros casos. Mas é também neste momento que a personagem-narradora se dá conta de que conhece alguém que está trabalhando para a construção de uma "nova e outra História" 25: Negro Alírio. Assim, MariaNova assume a condição de escritora dessa nova história, não reduzida às lições escolares: "era uma história vida que nascia das pessoas, do hoje, do agora" 26.

Se o confronto com a morte é uma constante no percurso de Maria-Nova, o fato de isso novamente ocorrer já no momento em que a personagem-narradora assume a posição de agente transformadora implica uma experiência epifânica. Isso é acentuado pelas circunstâncias em que falece Cidinha-Cidoca: a "louca mansa" morre de "não viver", engolida pelo Buracão que crescia na favela. Tratase, portanto, de uma morte inexplicável: além de o Buracão não ser muito profundo, a lama e o mato amorteciam as quedas; ademais, não havia marca nenhuma no corpo da morta que pudesse explicar o acontecido.

Assoma, portanto, a dimensão alegórica do desaparecimento de Cidinha-

\footnotetext{
${ }^{23}$ EVARISTO, 2017b, p. 140.

${ }^{24}$ EVARISTO, 2017b, p. 150.

${ }^{25}$ EVARISTO, 2017b, p. 150.

${ }^{26}$ EVARISTO, 2017b, p. 150-151.
} 
Cidoca: ela, que outrora "representara a vida na favela" ${ }^{27}$, cujo corpo era indissociável do sexo e do prazer, primeiro sucumbira à loucura; agora, finalmente encontrara a morte no Buracão que se alimentava do esvaziamento da favela ${ }^{28}$. Ao desvelar esse sentido, recuperando sua trajetória pessoal e a de seus semelhantes, Maria-Nova compreende que todos estavam destinados àquele mesmo fado: morrer de não viver. Em uma das cenas mais potentes do livro ${ }^{29}$, Maria-Nova toma a decisão de "viver do viver", materializada no gesto em que se fita no pedaço de espelho, acaricia o próprio rosto e desmancha as tranças de seu cabelo; ato, portanto, em que assume um profundo compromisso consigo mesma, tomando por exemplo aqueles que não cediam ao desespero - Vó Rita, Bondade e Negro Alírio. Abraçando a si mesma, Maria-Nova escolhe a vida, recusando a condenação à morte que lhe fora imposta enquanto mulher, negra e favelada.

\section{Maria-Nova contra o fascismo}

As últimas páginas de Becos da Memória estão permeadas de despedidas que assinalam a etapa final do desfavelamento. Para Maria-Nova, elas implicam a derrocada das últimas certezas e a consumação das inevitáveis rupturas. Tio Totó, que todos acreditavam ser eterno, morre ${ }^{30}$; Bondade, que Maria-Nova considerava um hóspede permanente, parte para outras bandas ${ }^{31}$. De especial importância, no entanto, é a despedida de Vó Rita e da Outra, porque implica uma superação pessoal: vencendo o medo e o asco, Maria-Nova as visita, abraçando e beijando Vó Rita como se estivesse abraçando e beijando também a Outra ${ }^{32}$. Por conseguinte, ao aceitar a si mesma, Maria-Nova encontra a condição necessária para ultrapassar os próprios temores e descobrir o amor - o que se confirma na aparição de Vó Rita, em sono-sonho, abrindo a blusa e expondo o coração através da pele negra ${ }^{33}$.

\footnotetext{
${ }^{27}$ EVARISTO, 2017b, p. 158.

${ }^{28}$ Sobre a dimensão simbólica do Buracão, ver Fonseca (2017).

${ }^{29}$ EVARISTO, 2017b, p. 160.

${ }^{30}$ EVARISTO, 2017b, p. 176.

${ }^{31}$ EVARISTO, 2017b, p. 178.

32 EVARISTO, 2017b, p. 182.

${ }^{33}$ EVARISTO, 2017b, p. 183.
} 
Retomando as considerações apresentadas na seção introdutória, encerro este artigo propondo algumas reflexões sobre o sentido da ação política de MariaNova nos tempos atuais.

Ao propor uma arte de viver contrária a todas as formas de fascismo, tanto as já instaladas quanto as porventura vindouras, Michel Foucaul $\mathrm{t}^{34}$ formula um conjunto de princípios essenciais, dentre os quais destaco: a necessidade de se libertar a ação política das paranoias unitárias e totalizantes; a preferência pela multiplicidade, pela diferença, e pelos agenciamentos móveis; o investimento na força revolucionária decorrente da ligação do desejo com o real; a procura da desindividualização; e, finalmente, uma relação desapaixonada com o poder pelo qual, no dizer de Foucault, não se deve "cair de amores". Importa relembrar que esses princípios dizem respeito à vida cotidiana - porque se trata, afinal, de combater o fascismo que se abriga em nossos discursos e atos.

Como Gilles Deleuze e Félix Guattari, autores da obra por ele prefaciada, Foucault percebeu que o fascismo está associado ao desejo; mais propriamente, ao desejo de poder - ao desejo que deseja a repressão, que deseja aquilo que nos domina e nos explora. Desse modo, Foucault chama a atenção para a relativa impropriedade em se pensar o fascismo como uma ditadura: sem uma adesão da população às tarefas de policiamento, de repressão e de controle, o fascismo não é possível ${ }^{35}$. Em outras palavras: o fascismo encontra sustentação em uma rede política constituída por indivíduos que, movidos pelo amor ao poder, fomentam as estruturas opressoras.

Em Becos da Memória, é fácil perceber a presença do poder repressor no desfavelamento, imposto pelo estado como estratégia necropolítica ${ }^{36}$, ou em um personagem como o Fuinha, disposto a matar sua esposa e violentar sua filha ${ }^{37}$. Todavia, quero chamar a atenção para uma figura, em particular: Maria Esmeralda - a menina negra, colega de sala de Maria-Nova, entregue ao silêncio e ao alheamento, incapaz de propor quaisquer questionamentos que manifestem um olhar crítico sobre o mundo. A passividade da colega não apenas ilustra a resignação imposta pelo poder, mas também tem consequências coercitivas: é o

\footnotetext{
${ }^{34}$ FOUCAULT, 1977.

${ }^{35}$ FOUCAULT, 2009 [1974].

${ }^{36}$ Cf. MBEMBE, 2018.

${ }^{37}$ EVARISTO, 2017b, p. 77-80.
} 
que inibe, num primeiro momento, a reação de Maria-Nova - que silencia, calada pela paranoia, intimidada pelo discurso que veda a crítica do real e impede qualquer ação transformadora.

Não obstante, Maria-Nova consegue reagir contra essa situação a partir de sua disposição para a alteridade: suas relações empáticas com as pessoas que a cercam determinam um processo de desindividualização; a rede de afetos que constrói permite que acolha a diferença, vencendo as paranoias; e é assim que a personagem-narradora encontra as condições necessárias para construir uma ação política de sentido revolucionário. Ouvindo e escrevendo, aprendendo e ensinando, acolhendo e partilhando, Maria-Nova se converte em uma potência transformadora, em uma relação permanente de troca com aqueles e aquelas que a rodeiam.

Embora o desfavelamento se concretize, Maria-Nova mantém no coração uma esperança enraizada na ancestralidade - sintetizada, sobretudo, na figura de Vó Rita -, o que permite vislumbrar a (re)construção do mundo a partir de baixo: de uma humanidade que, apesar de todas as dores e misérias, encontra em si mesma as forças necessárias para seguir em frente, movida pelo amor fundamental à liberdade. Será essa, talvez, sua mais valiosa lição para nós, a quem cabe prosseguir na luta contra todas as expressões do fascismo.

\section{Referências}

EVARISTO, Conceição. Ponciá Vicêncio. Rio de Janeiro: Pallas, 2017a.

. Becos da Memória. $3^{\text {a }}$ ed. Rio de Janeiro: Pallas, 2017b.

FONSECA, Maria Nazareth Soares. Posfácio: costurando uma colcha de memórias. In: EVARISTO, Conceição. Becos da Memória. 3.ed. Rio de Janeiro: Pallas, 2017.

FOUCAULT, Michel. Introdução à vida não-fascista. In: DELEUZE, Gilles; GUATTARI, Félix. Anti-Oedipus: Capitalism and Schizophrenia. New York: Viking Press, 1977.

Anti-retro. In: Estética: literatura e pintura, música e cinema. Ditos e escritos, III. 2. ed. Rio de Janeiro: Forense Universitária, 2009 [1974].

GLARE, P. G. W. (ed.). Oxford Latin Dictionary. 2. ed. Oxford: Oxford University Press, 2012.

MBEMBE, Achille. Necropolítica: biopoder, soberania, estado de exceção, política 
da morte. São Paulo: n-1 edições, 2018.

OLIVEIRA, Luiz Henrique Silva de. O romance afro-brasileiro de corte autoficcional: "escrevivências" em Becos da Memória. In: DUARTE, Constância Lima; CÔRTES, Cristiane; PEREIRA, Maria do Rosário A. (org.) Escrevivências: identidade, gênero e violência na obra de Conceição Evaristo. 2.ed. Belo Horizonte: Idea, 2018.

SAMYN, Henrique Marques. Por uma revolução antirracista: síntese histórica e trajetória ideológica do Partido Pantera Negra. In: (org.). Por uma revolução antirracista: uma antologia de textos dos Panteras Negras (1968-1971). Rio de Janeiro: edição do autor, 2018.

Henrique Marques Samyn é Professor Adjunto do Instituto de Letras da Universidade do Estado do Rio de Janeiro, atuando na graduação e na pósgraduação. Suas pesquisas abordam modos de representação de subjetividades e corpos generificados e racializados, desde uma perspectiva interseccional. Coordena o projeto de extensão Letras Pretas, voltado ao estudo e divulgação da produção literária, cultural e intelectual de autoria negra e feminina, desenvolvido com estudantes negras da UERJ.

Recebido em 25 de fevereiro de 2020. Aprovado em 02 de abril de 2020. 